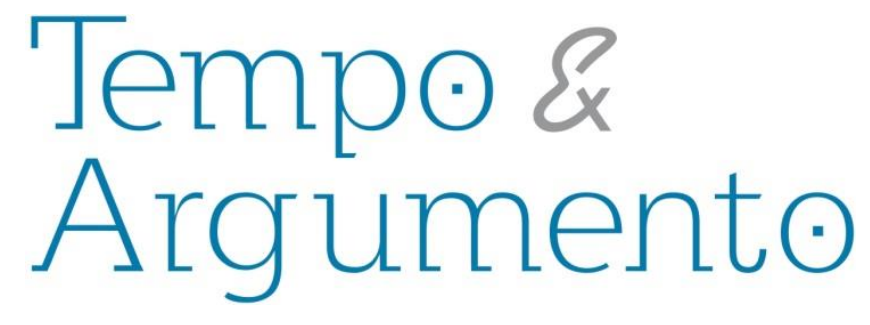

\title{
A estrutura ontológica do tempo presente*
}

\section{Resumo}

A História do Tempo Presente mobiliza epistemologicamente um conceito de presente específico. Não obstante a estrutura ontológica do conceito de presente não ser autoevidente, enquanto conceito, isto é, como elaboração intelectual, pode-se determiná-lo por uma investigação de sua história. Objetiva-se, portanto, descobrir a história do conceito de presente de uma perspectiva ontológica, expor sua natureza de limite-criativo do tempo, bem como sua forma infinita, eterna. Martin Heidegger rompe com essa maneira tradicional de interpretar o fenômeno do tempo ao questionar a natureza do modus temporal presente legado pela filosofia. Nesses termos, o argumento final sublinha a reviravolta sofrida pela noção de presente em Heidegger como movimento central para a justificação teórica do campo historiográfico da História do Tempo Presente.

Palavras-chave: Presente. Tempo. Ontologia.

\author{
Augusto Bruno de Carvalho Dias Leite \\ Doutor em História pela Universidade \\ Federal de Minas Gerais (UFMG) com \\ período sanduíche na Ecole des Hautes \\ Études en Sciences Sociales. Estágio Pós- \\ Doutoral na Universidade Federal do \\ Espírito Santo (UFES). \\ Vitória - ES - BRASIL \\ augustobrunoc@yahoo.com.br
}

\section{Para citar este artigo:}

DE CARVALHO, Augusto. A estrutura ontológica do tempo presente. Tempo e Argumento, Florianópolis, v. 10, n. 24, p. 43 - 63, abr./jun. 2018.

DOI: $10.5965 / 2175180310242018043$

http://dx.doi.org/10.5965/2175180310242018043

\footnotetext{
* Registro o meu agradecimento à CAPES e à FAPES pelo financiamento da pesquisa.
} 


\begin{abstract}
The History of Present Time epistemologically mobilizes one specific concept of present. Although the ontological structure of the concept of present is not self-evident, as a concept, i. e., as an intellectual elaboration, it can be determined by an investigation of its own history. Therefore, this paper aims to discover the history of the concept of present from an ontological perspective, to expose the present as the creative-limit nature of time, as well as its infinite or eternal form. Martin Heidegger breaks with this traditional way of interpretating the time as a phenomenon by questioning the very nature of presence bequeathed by the philosophy of time. In these terms, the final argument underlines the turnaround on the notion of present in Heidegger work as central to the theoretical justification of the historiographical field that deals with the Present Time.
\end{abstract}

Keywords: Present. Time. Ontology.

\title{
Apresentação do problema
}

Ao menos desde o afamado vaticínio de Benedetto Croce (1943), que diz toda história ser contemporânea a chamada História do Tempo Presente impõe, gradativamente, sua pertinência no campo dos estudos históricos. Todavia, é preciso sublinhar que para este efeito há um determinado conceito de presente mobilizado pelos teóricos da História do Tempo Presente que pressupõe certa ideia de tempo bastante precisa. 
Gostaria, portanto, de mapear a qual conceito de presente e a qual ideia de tempo esta forma historiográfica se refere para que sua justificação teórica se sustente, particularmente em relação à estrutura ou arquitetura ontológica da temporalidade. Em função disso, a perspectiva que será aqui desenvolvida não pretende repetir os argumentos de François Dosse (2012) que em "História do Tempo Presente e Historiografia" elaborou uma detalhada descrição do pressuposto epistemológico da historiografia do tempo presente, sobretudo a partir das contribuições de Paul Ricoeur e suas afinidades com a hermenêutica histórica de Hans-Georg Gadamer, mas também com as reflexões meta-históricas de Reinhardt Koselleck. Diferentemente de Dosse, destarte proponho explorar a ontologia do tempo; não sua manifestação epistemológica, mas a estrutura que o presente apresenta para que seja compreendido e explicado como tal, em um diálogo direto com filósofos que investigaram o problema do tempo segundo a perspectiva ontológica.

O objetivo desta curta argumentação é, além de traçar o itinerário do conceito de presente dentro da história das ideias, esclarecer sua natureza através do descobrimento de sua história e criar, assim, dispositivos de justificação teórica daquilo que já se articulou epistemologicamente, a saber, o estudo do tempo presente. Dito isso, se há alguma tradição a qual a breve história do conceito de presente aqui esboçada pode se filiar, talvez seja à maneira de Joachim Ritter, cuja história dos conceitos se refere mais à vida própria das ideias e conceitos que ao contexto factual e histórico ao qual tais ideias ou conceitos se correspondem. Deste modo, privilegio a configuração do problema do fenômeno do presente como elaboração conceitual, isto é, intelectual, e o seu desenvolvimento.

Por fim, sabemos que Tucídides, deliberadamente, já fazia história no tempo presente (Cf. DOSSE, 2012). Contudo, sublinho o fato de denominar História do Tempo Presente o que o professor Carlos Fico chamou de sua "versão do século XX" (FICO, 2016, p. 274), que, ocupada com duas questões essenciais - o papel da memória e dos eventos traumáticos na constituição do mundo histórico - constituiu-se como um campo do saber histórico a partir da fundação do Institut d'Histoire du Temps Présent, em 1978. 


\section{Origem do conceito de presente segundo a tradição ontológica da ideia de} tempo

\section{O agora de Aristóteles}

Aristóteles, o estagirita, foi, sem dúvida, o primeiro filósofo a elaborar de forma sistemática a estrutura ontológica do tempo, mais precisamente a sua natureza ${ }^{2}$, sua

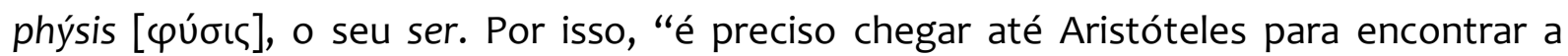
primeira análise filosófica exaustiva e sistemática do tempo" (LLOYD, 1975, p. 159). A partir de uma investigação sobre a natureza do movimento, Aristóteles, na Física, conclui que o tempo é primordialmente a relação entre um antes e um depois, unificados e separados, simultaneamente, por um agora [vũv; nûn], pois o princípio fundamental do movimento é o "antes-e-depois no tempo, em virtude da dependência do tempo sobre o movimento" (Física, IV (11), 219 a - 15). Logo, o "agora é um limite [divisor] do tempo" (Física, IV (10), 218 a - 25), de acordo com Aristóteles; “é o 'agora' que demarca o tempo como anterior e posterior" (Física, IV (11), 219 b - 15-16). O agora, pois, como "acidente" (Física, IV (11), 220 a - 21), ou seja, não como uma porção de tempo ou matéria temporal, mas “em seu caráter geral de limite (...) é de uma só vez o início do tempo vindouro e o fim do tempo que passa" (Física, IV (13), 222 a - 12-14); sem ser, todavia, exatamente tempo. Conforme Paul F. Conen, em Die Zeittheorie des Aristoteles (1964), “o agora faz o tempo algo contínuo e também dividido" (CONEN, 1964, p. 63), porque ele une e divide o tempo, ele extingue e também cria o tempo, precisamente ao criar duas porções de tempo, o antes e o depois. Tal como repete Aristóteles em Categorias, uma vez que estes

\footnotetext{
${ }^{1}$ As traduções de Aristóteles, quando não forem de responsabilidade do autor, referem-se à tradução do professor Fernando Rey Puente (Cf. ARISTÓTELES, 2014). Nota-se, antes de mais nada, que naturalmente não serão esboçados aqui todos os conceitos de presente, mas somente os dois conceitos - o de Aristóteles e o de Agostinho - que sobrevivem como os fundamentos axiomáticos daquilo que poderíamos nomear como a ideia de tempo própria à modernidade, seja no discurso histórico, filosófico, científico ou até mesmo hodierno. De toda forma, uma investigação mais detalhada sobre a tradição ontológica da ideia de tempo em geral pode ser encontrada em minha tese de doutorado (DE CARVALHO, 2017), cujo presente artigo é um desdobramento temático secundário, porém imediato em relação ao conteúdo teórico.

2 "A Física de Aristóteles é, até onde se sabe, o primeiro trabalho que almeja uma filosofia da natureza sistemática e unificada" (WEIGELT, 2014, p. 157).
} 
Finalmente, à vista disso, pode-se chegar à fórmula fundamental de Aristóteles sobre a natureza do tempo: "Quando <nós percebemos> o anterior-posterior, então nós falamos de tempo. Com efeito, isto é o tempo: número de um movimento segundo o

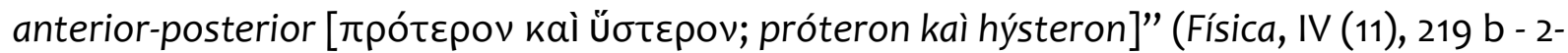
3). E este "anterior-posterior é primeiro no lugar [tópos]" (Física, IV (11) 219a, 14-15). Em Categorias, o estagirita repete: “Pode-se dizer também que as partes do tempo são entre elas certo lugar [tópos], porque no tempo certa parte é anterior, certa parte posterior" (Categorias, 5 a -14). Como limite-divisor, o agora, como conceito intemporal que faz do tempo existente, é o “lugar [tópos]” (Física, IV (4) 212 a - 2) do tempo, “imóvel” (Física, IV (4), 212 a - 20), segundo a Física. Afinal, o agora não passa, precisamente ao articular o anterior-posterior, permitindo a "passagem" do tempo.

Aristóteles, com efeito, desenha uma estrutura ontológica para o tempo e produz um conceito específico de agora, que, conforme sinalizado, apesar de ser o seu centro articulador ou catalizador, sua origem, não compõe o tempo; mas seria um momento transicional, um limiar necessário entre o anterior e o posterior; nesse sentido, é tempo o passado e o porvir, mas não o presente. O agora aristotélico, momento ou presente, não pertence ao tempo, mas é somente uma noção ou fórmula conceitual que permite explicar o tempo como fenômeno natural, pois "um anterior e outro posterior, dizemos isso ser o tempo" (Física, IV (11), 219 a - 26-29). Nota-se ainda que o agora, na qualidade de lugar, é imóvel por natureza, limite, pois quem se move são as partes anterior e posterior, que se chamam tempo.

O agora, portanto, enquanto limite não é tempo, mas um acidente <deste>; enquanto numera, porém, ele é número. Com efeito, os limites pertencem somente àquilo de que são limites (...).

É manifesto, então, que o tempo é número de um movimento segundo o

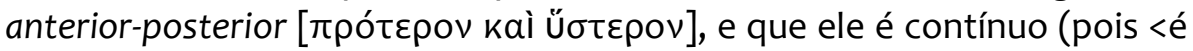
número de> um contínuo). (Física, IV (11), 220 a - 21-16) ${ }^{3}$

\footnotetext{
3 O tempo, então, como "medida do movimento" (Física, IV (12), 221 b - 8), é numerável, e o agora, apesar de não ser tempo, é número, porque enquanto número é nulo, ou seja, o agora é o "zero". Contudo, tal discussão sobre as implicações do aspecto numérico do tempo não será objeto de análise neste artigo.
} 
A função do agora, então, é a de "unificação e separação do continuo do tempo" (CONEN, 1964, p. 115). Em relação ao agora como "número", Martin Heidegger, em Die Grundprobleme der Phänomenologie, de 1927, ensina que mais do que limite [péras], quer dizer, além de limite, o agora deve ser entendido como número [arithmós], de acordo com Aristóteles.

[O] limite de algo pertence ao modo de ser do limitado. Isto não é válido para o número. Ele não está preso àquilo que ele conta. O número pode determinar algo, sem que ele seja por sua parte dependente da materialidade e do modo de ser do que é contado. Posso dizer: dez cavalos. Aqui, em verdade, o número dez determina os cavalos, mas o número dez não tem nada do caráter dos cavalos enquanto cavalos; pois posso determinar numericamente com eles do mesmo modo barcos, triângulos ou árvores.

(HEIDEGGER, 2005, p. 363)

O agora, assim, comporta-se como limite-criativo, quer dizer, ele divide o tempo entre o anterior e o posterior e, precisamente por dividir, o agora cria o pretérito e o futuro ao seccionar o movimento; o agora, então, cria o tempo paradoxalmente ao limitálo como anterior-posterior. E tais operações são unitárias, indissociáveis uma da outra.

Nota-se, à guisa de conclusão, que a fórmula "próteron kaì hýsteron" [anteriorposterior] sobreviverá como axioma por gerações de pensadores ao se tornar uma ideia de capilaridade incalculável. A título de exemplo, Ibn Sina (Avicena) e Ibn Rushd (Averróes), discutem o tempo enquanto numerus motus secundum prius et posterius (ASSMANN [et al], 2004, p. 1212) séculos após a publicização do tratado sobre o tempo de Aristóteles. Tomás de Aquino repetirá este adágio aristotélico adaptando-o à doutrina cristã da eternidade divina (Summa Theologice, Q. 10, Art.1-5). David Hume, no século XVIII, fará sobreviver na filosofia moderna o axioma aristotélico do tempo ao propor que "todo momento deve ser distinguido como posterior ou anterior em relação a outro" (HUME, 1739, p. 26). William James reproduz, no que veio a ser chamada de filosofia analítica, a caracterização aristotélica do tempo em The Principles of Psychology (1890): 
Então a memória se enche de coisas datadas - datadas no sentido de ser antes ou depois de algo. A data de algo é uma mera relação de antes ou depois da coisa presente ou alguma coisa passada ou futura. (...) Mas o protótipo e modelo original de todos os tempos concebidos é o presente capcioso [specious], ilusório, a duração pequena a qual somos incessantemente e imediatamente sensíveis.

(JAMES, 1890, p. 231)

Ou seja, a "relação fundamental da qual o conceito de tempo deriva é a relação 'antes-e-depois"' (ZWART, 1972, p. 135), sendo o agora essa “ilusão" ou "acidente”, o conceito-chave, aquele que produz de fato o que se chama tempo, sua origem-criativa de acordo com Aristóteles ${ }^{4}$.

\section{O presente de Agostinho ${ }^{5}$}

Agostinho de Hipona, reconhecidamente um teórico da ideia de tempo medular, segue os passos do estagirita, corroborando sua tese fundamental, o axioma anteriorposterior, e avança em alguns pontos essenciais que produzem o efeito de uma ontologia do tempo própria, precisamente em suas Confissões. No livro XI, particularmente, Agostinho desdobra uma série de questionamentos que inauguram o que poderíamos chamar no vocabulário moderno de psicologia do tempo.

A análise da consciência do tempo é desde sempre a cruz da psicologia descritiva e das teorias do conhecimento. O primeiro a sentir profundamente as dificuldades consideráveis desse trabalho a ponto de atingir o desespero fora Agostinho. Ainda hoje, qualquer um que se preocupe com o problema do tempo deverá estudar a fundo do capítulo 13 ao 28 do XI livro das Confissões.

(HUSSERL, 1928, p. 368)

A partir de um movimento introspectivo que interroga imediatamente a natureza da divindade, na XI confissão, Agostinho acaba por descobrir que tal questionamento

\footnotetext{
${ }^{4}$ Pode-se acrescentar, ainda, pensadores como G. W. F. Hegel e Albert Einstein nesta mesma tradicional maneira de pressupor a estrutura ontológica funtamental do tempo. Afinal, Einstein não deixa de reafirmar "a distinção entre antes-depois" (EINSTEIN, 1979, p. 511) como o fundamento da ideia de tempo em suas proposições sobre a relatividade do tempo "restrita" e "geral". Tampouco Hegel desabona a máxima agostiniana que afirma o "presente verdadeiro" evidentemente tal qual a "eternidade" (Cf. HEGEL, 1986, 9, §259).

${ }^{5}$ As traduções de Agostinho, quando não forem de responsabilidade do autor, referem-se à tradução do professor José Baracat Júnior (Cf. AGOSTINHO, 2014).
} 
(MEIJERING, 1979, p. 115), Agostinho descobre que "uma ontologia da eternidade seria, portanto, em última instância uma ontologia de Deus" (WEIS, 1984, p. 104).

Para efeito prático, propõe-se uma leitura filosófica e psicológica, antes de teológica, do argumento agostiniano. E no que se refere ao conceito de presente, há uma difícil intersecção entre o conteúdo teológico e psicológico na sua meditação sobre o tempo. O presente, para Agostinho, possui o passado e o futuro, de modo muito semelhante a Aristóteles. Contudo, ao contrário do agora aristotélico, que inexiste no plano natural, mas somente existe de modo conceitual, caracterizado como fórmula que permite entender ou explicar o tempo, pois o agora é intemporal; o presente para Agostinho é justificado como tal somente por sua condição atemporal, quer dizer, porque ele existe sempre, conforme a natureza eterna da divindade, sendo o modus temporal presente a sua expressão material imediatamente sensível.

(...) precedes [Deus] todos os passados com a celsitude da tua eternidade sempre presente [praecedis omnia praeterita celsitudine semper praesentis aeternitatis], e superas todos os futuros porque são futuros e, quando vierem, serão passados; entretanto tu és sempre o mesmo, e os teus anos não morrem.

(Confissões, $\mathrm{XI}, 16$ )

A ontologia da divindade que se confunde com uma ontologia do tempo, que é eternamente presente, é o tom fundamental da reflexão agostiniana sobre a natureza do tempo, que no limite, se confunde com o próprio presente.

Que é, portanto, o tempo? Se ninguém me pergunta, sei; se quiser explicar a quem pergunta, não sei: com confiança, no entanto, digo que sei que, se nada passasse, não haveria tempo passado e, se nada adviesse, não haveria tempo futuro, e se nada houvesse, não haveria tempo presente. Esses dois tempos, portanto, o passado e o futuro, de

\footnotetext{
${ }^{6}$ Cito uma passagem da Tanakh que resume a natureza eterna da divindade hebraico-cristã de modo análogo ao argumento de Agostinho: "antes que nascessem os montes, ou que tivesses formado a terra e

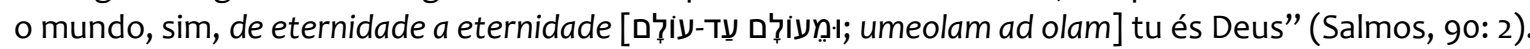


que modo existem, quando o passado já não existe e o futuro ainda não existe? Entretanto, se o presente fosse sempre presente, sem transir ao passado, não seria tempo, mas eternidade. [Praesens autem si semper esset praesens nec in praeteritum transiret, non iam esset tempus, sed aeternitas].

(Confissões, $\mathrm{XI}, 17$ )

E conclui, dessa maneira, Agostinho:

O que agora é evidente e claro, é que não há nem coisas futuras, nem passadas, nem se diz propriamente: há três tempos, passado, presente e futuro, mas talvez se diga propriamente: há três tempos, o presente relativo às coisas passadas, o presente relativo às presentes, $e$ o presente relativo às futuras [tempora sunt tria, praesens de praeteritis, praesens de praesentibus, praesens de futuris]. Esses três estão na alma [in anima] e não os vejo em outro lugar: a memória é o presente relativo às coisas passadas; a intuição ou visão, o presente relativo às presentes; a expectativa, o presente relativo às futuras [praesens de praeteritis memoria, praesens de praesentibus contuitus, praesens de futuris expectatio] $]^{7}$.

(Confissões, $\mathrm{XI}, 26$ )

Nesses termos, a "alma possui sua existência em um presente indivisível, mas tem o poder de distender-se, então, em duas direções, rumo ao futuro por meio da antecipação e rumo ao passado por meio da memória” (CALLAHAN, 1948, p. 177). E “o agora, que é a fronteira do tempo, é a atenção presente da alma (...). Esta atenção presente é o limite entre o futuro e o passado, quer dizer, uma vez que seu tempo é psicológico, entre a antecipação da alma e a memória" (CALLAHAN, 1948, p. 179). O resultado pouco explorado dessa conhecida meditação de Agostinho é a formulação de um conceito de presente que, antes de sedimentar o tempo de modo radicalmente humano, expressa a eternidade, pois surge nas Confissões como a justificativa mais clara e evidente da existência da divindade, sua manifestação de modo temporal, o presente, a eternidade sempre presente [semper praesentis aeternitatis]. Porque como fenômeno, de

\footnotetext{
7 "É a introspecção apaixonada de santo Agostinho que projeta pela primeira vez a luz da experiência interior que a alma tem dela mesma, em sua corrida ao encontro do futuro, sobre os paradoxos ontológicos do tempo (...) ele revela a dimensão da interioridade e tem por tema de reflexão não mais o tempo em si, mas a consciência do tempo, situando a dimensão existencial do tempo na tensão espiritual (distentio animi) entre distração e concentração, medo, esperança e arrependimento" (GADAMER, 1978, p. 47).
} 
característica do que se nomeia como o modus temporal presente (semper praesentis aeternitatis [eternidade sempre presente]) afirma o conceito de presente como "eterno não meramente no sentido de não ter nem começo nem fim, mas também no sentido de não ser sucedido nem pelo passado nem pelo futuro, portanto há somente o presente permanente [abiding]" (TESKE, 1996, p. 14) (Cf. O’DONNELL: 1992, p. 250). Tempo é justificado como eternidade através do conceito de presente de Agostinho, pois "o seu hoje é a eternidade" [Hodiernus tuus aeternitas] (Confissões, XI, 16 - 13).

\section{Ou o presente não existe ou é eterno}

Aristóteles e Agostinho fundamentam axiomaticamente o presente como a origem do fenômeno do tempo, a partir da lógica filosófica e das evidências do estudo de sua natureza.

Agostinho afirma a substância divina como o presente, compreendido como manifestação da própria eternidade: "aeternitas ipsa dei substantia est [a eternidade é a substtancia divina]" (O’DONNELL, 1992, p. 253), conforme a tradição teológica exigia, mas não havia justificado pelo prisma filosófico, tal como Agostinho o faz. O tempo, nesses termos, é mero vestigium ou imitatio da eternidade (O’DONNEL, 1992, p. 278), e a divindade se manifesta na forma do modus temporal presente; assim como Platão (2010), no Timeu, já sinalizava, quando afirma que o demiurgo, na qualidade de "deus eterno" (Timeu, 37C-D), produziu uma "imagem móvel da eternidade", o tempo ${ }^{8}$. Em um contraste claro com Aristóteles, para quem o tempo é a relação anterior-posterior, o tempo para Agostinho é o eterno presente. Diferentemente de Aristóteles, portanto, o presente de

\footnotetext{
8 "mesmo que fosse eterna a natureza do Ser Vivo [demiurgo], era impossível conferi-la plenamente a qualquer coisa gerada; portanto, ele concebeu produzir uma imagem móvel da eternidade, e à medida que ordenava o céu, ele produziu, simultaneamente, uma imagem eterna [aiônion eikôna] daquela eternidade que permanece na unidade, e essa imagem se movendo de acordo com o número, mesmo o que chamamos de tempo [khrónon] (...). O tempo portanto, veio a ser (foi gerado) simultaneamente ao céu (universo)" (Timeu, 37D).
} 
O agora aristotélico, todavia, pode ser compreendido como presente por uma operação de associação que encontra uma coincidência em suas duas formas (Cf. CONEN, 1964, p. 72), segundo a interpretação já antiga de Walter Bröcker, em Aristoteles, obra de 1935. Porque "o ser-agora é sempre outro ser. Cada ponto no tempo foi primeiro futuro, vem ao presente e chega ao passado. (...) [O] presente (agora) não permanece ele mesmo como um ponto no tempo, ao contrário ele vai de um ponto no tempo (agora) até outro" (CONEN, 1964, p. 81), isto é, o agora, mesmo na qualidade de conceito-limite, possui a mesma forma fenomênica que o presente ilimitado de Agostinho. O que se quer dizer, de modo claro, é a natureza paradoxal do fenômeno da presença, que pode tanto se expressar como forma vazia (Aristóteles) quanto como forma ilimitadamente preenchida (Agostinho).

Ambos os conceitos de presente, de Aristóteles e Agostinho, tornam-se o fundamento daquilo que podemos chamar de ideia tradicional de tempo, compõem a ontologia tradicional da ideia de tempo. John Ellis McTaggart, em seu conhecido "The unreality of time" (1908) identifica de fato duas estruturas ou séries fundamentais que a filosofia produziu para explicar o fenômeno do tempo, quais sejam, a série A, que elaborou a conjunção passado-presente-futuro, e, por outro lado, a série B, que explica o tempo a partir da conexão anterior-posterior. Não é preciso dizer que a série A orienta-se pelos argumentos das Confissões de Agostinho e a série B pelos da Física de Aristóteles. E evidentemente são estas as duas perspectivas sobre o tempo que sobrevivem como os fundamentos da ontologia tradicional da ideia de tempo, sendo o conceito de presente (Agostinho) ou agora (Aristóteles) das duas maneiras de compreensão do fenômeno do tempo, a matéria ontológica de tudo aquilo que se adjetiva ou se define de modo infinitesimal como a presença do tempo ou o presente em geral.

De modo contraditório, portanto, o agora, mesmo que factualmente inexistente, como lugar do tempo em geral, caracteriza o fenômeno do tempo presente, tal qual o presente de Agostinho manifesta a natureza eterna da existência. Ambos produzem, ao 
Aberto Caeiro, pela pena de Fernando Pessoa, sumariza o conceito que, conforme a tradição ontológica da ideia de tempo, sedimentada por Aristóteles e Agostinho, produz a antinomia de existir eternamente sem nem mesmo existir:

Vive, dizes, no presente;

Vive só no presente.

Mas eu não quero o presente, quero a realidade;

Quero as coisas que existem, não o tempo que as mede.

O que é o presente?

É uma coisa relativa ao passado e ao futuro.

É uma coisa que existe em virtude de outras coisas existirem.

(Alberto Caeiro, Poemas Inconjuntos)

Ou como T. S. Eliot de modo mais agostiniano que aristotélico diz:

Tempo presente e tempo passado

São ambos talvez presente no tempo futuro,

E o tempo futuro contido no tempo passado.

Se todo tempo é eternamente presente

Todo tempo é irremediável.

(...)

Tempo passado e tempo futuro

o que poderia ter sido e o que foi

Apontam para um fim, que é sempre presente.

(T. S. Eliot, Burnt Norton) ${ }^{9}$

\section{A ruptura com a tradição ontológica da ideia de tempo em Martin Heidegger}

Mais do que as estruturas ontológicas totais do tempo, o conceito de presente e sua função permaneceram inalterados, de seu advento ontológico em Aristóteles e Agostinho, particularmente, até Martin Heidegger. O próprio Heidegger ensina que “[o] tratado aristotélico sobre o tempo é a primeira interpretação circunstanciada desse fenômeno que nos foi legada. Ela determinou em essência toda a concepção posterior do

\footnotetext{
9 "Time present and time past / Are both perhaps present in time future, / And time future contained in time past. / If all time is eternally present / All time is unredeemable. / (...) Time past and time future / What might have been and what has been / Point to one end, which is always present."
} 
No âmbito da historiografia, em um dos esforços mais elementares do que podemos chamar hoje de "teoria da história", a Historik, de Johann Gustav Droysen, averiguamos a arquitetura aristotélico-agostiniana do objeto conceitual do historiador moderno. Droysen, em meados do século XIX, conforme muitos outros historiadores farão, já afirma que

o objeto da pesquisa histórica não são os passados, pois estes passaram, ao contrário são coisas que aqui e agora, persistem, podem ser suas memórias do que foi e aconteceu, ou os restos dos acontecimentos e eventos.

$(\text { Historik, §5) })^{10}$

O espírito finito possui apenas o agora e o aqui. Mas esse pobre limite do seu ser, ele estendeu para frente, com as suas vontades e esperanças, para trás com a plenitude das suas memórias. Assim, idealmente, 0 futuro e o passado, associando-se, têm como análogo a eternidade.

(Historik, §6)

Com efeito, lembra Jacques Derrida, em Marges de la Philosophie (1972), que

de Parmênides à Husserl, o privilégio do presente nunca foi colocado em questão. Não poderia ser. Ele é a própria evidência e nenhum pensamento parece possível fora de seu elemento. A não-presença é sempre pensada na forma da presença (é suficiente dizer na forma) ou como modalisação da presença. O passado e o futuro são sempre determinados como presentes passados ou presentes futuros. (DERRIDA, 1972, p. 36-37)

Quando Heidegger, apesar disso, descobre a transitividade do verbo e substantivo ser, em Sein und Zeit (1927) - sua maior descoberta, segundo Emmanuel Levinas (1993) ${ }^{11}$-, o filósofo questiona a natureza do conceito de presente de modo que seu estatuto ontológico de lugar original do tempo, limite-criativo inquestionável e eterno do fenômeno temporal, perde o seu sentido lógico em direção a uma nova estrutura, mais plástica que estática: ekstática, para ser mais exato, no sentido de por-se para fora;

\footnotetext{
${ }^{10}$ Segundo a edição crítica da Historik, organizada por Peter Leyh (Cf. DROYSEN, 1977).

${ }^{11}$ A "transitividade do verbo ser é a maior descoberta de Heidegger" (LEVINAS, 1993, p. 53).
} 
porque o fenômeno do tempo é antes de mais nada, por definição, transitório, nunca estático, segundo a própria tradição ontológica. Heidegger propõe que o tempo, assim, não se caracteriza pela coincidência entre a presença, a verdade e o ser das coisas no presente, caracterizar-se-ia, ao contrário, pelo seu princípio mais básico, o movimento ininterrupto, este, sim, eterno, e sua não-filiação ao espaço, mas ao próprio tempo como sua evidência principal. O tempo deveria ser pensado pelo tempo, não pelo espaço, desvio filosófico aristotélico ${ }^{12}$, ou pela eternidade, desvido teológico agostiniano ${ }^{13}$.

Em Ser e Tempo, Heidegger foi guiado pela ideia de que na ontologia tradicional o Ser foi entendido principalmente tanto como presença-àmão quanto como presença contínua, e, assim, para uma das dimensões do tempo, nomeadamente o presente. Heidegger desejava trazer a unilateralmente acentuada 'presença contínua' de volta ao total, tempo pluridimensional, de modo a tentar entender o significado do Ser da experiência originária do tempo, nomeadamente a temporalidade.

(KOCKELMANS, 1992, p. 152)

Heidegger, ele mesmo, o diz:

O que quer dizer Ser? (...) a "questão-do-ser" vem do insight que os Gregos antigos pensam o ser como presença, em conjunto com a aletheia, ou seja, o descoberto, revelado. Enquanto eu ponderava esse pensamento, especialmente porque nesse meio tempo minha forma de ver tinha sido treinada na fenomenologia, consegui levar a questão um passo a frente da seguinte maneira: na medida em que a presença e o presente possuem seu caráter segundo o tempo, não deve, então, o sentido do ser receber seu significado do tempo? Tornou-se, assim, evidente que as determinações do tempo na filosofia desde Aristóteles têm sido levadas do ponto de partida do ser como presença.

(GA, I, 14, 147-148)

Nesse sentido, para redefinir o ser não mais como mera imutabilidade estática, eternidade sempre presente, mas a partir de seu caráter original finito, quer dizer, temporal, a ideia de tempo haveria de ser redescoberta, pois os conceitos de "futuro",

\footnotetext{
12 "Com efeito, o mais seguro parece ser abandonar simplesmente o campo representacional até aqui de espaço e tempo e de sua apreensão conceitual e começar de" (GA, III, 65, 372), segundo o § 239 das Beiträge zur Philosophie.

13 “(...) a teologia trata do "Dasein" (existência) humano como ser para Deus, de seu ser temporal em sua relação com a eternidade. (...) O filosofo não crê. Caso pergunte ao filósofo sobre o tempo, então ele está determinado a compreender o tempo a partir do tempo, quer dizer, em relação ao "sempre" (ákí), que se parece com a eternidade, mas que se evidencia como um mero derivado do ser temporal" (GA, III, 64, 107).
} 

toda terminologia ontológica" (HEIDEGGER, 2012, p. 889). O principado do presente, então, é alvo imediato da crítica heideggeriana à ideia de tempo segundo a ontologia tradicional.

Heidegger propõe o Augenblick [momento; instante] como real presença do tempo. E tal instante não haveria de se configurar conforme as leis agostinianas da distensão do pensamento em direção à memória ou de espera atenta em relação ao futuro; bem ao contrário, o conceito proposto por Heidegger diz que o tempo, em sua qualidade de potência de ser tempo, ou seja, temporalidade, nunca acontece como fenômeno senão pela antecipação (não a espera) do futuro, que em relação umbilical com o passado (a matéria existencial do tempo) se realiza instantaneamente. De uma forma ou de outra, Heidegger parece concordar com Aristóteles ao entender que o fundamento do tempo diz respeito à relação entre o anterior (passado) e o posterior (futuro), mas introduz alguns elementos que descobrem certos pontos ainda não evidenciados pelo estagirita. O "ser-do-sido surge do futuro, e de tal maneira que o sido ou melhor, que está sendo-sido - faz o presente resultar de si” (HEIDEGGER, 2012, p. 889). Portanto, o que Heidegger chamou de unidade ekstática ${ }^{14}$ do tempo - sua presença instantânea - é precisamente a unidade entre o futuro, a origem-criativa real do tempo, o passado ou a passeidade [Gewesenheit, traduzido muitas vezes como o ter-sido] e o agora, que instantaneamente realiza aquilo que podemos chamar de presença, pois "esse fenômeno [o tempo] é um fenômeno unitário, isto é, como futuro sendo-sido presencizante nós o denominamos temporalidade. (...) A temporalidade descobre-se como o sentido da preocupação própria" (HEIDEGGER, 2012, p. 889). O mais originário, assim, é o futuro, não o presente. A origem-criativa do tempo seria o futuro em relação com o passado, não o presente, seja ele a expressão factual do eterno (Agostinho) ou o espaço

\footnotetext{
14 "Denominamos, por isso, os fenômenos característicos futuro, ter-sido e presente de asestases da temporalidade. Esta não é primeiramente um ente que, em seguida, sai de si, mas a sua essência é a temporalização na unidade das estases" (GA, I, 2, 435).
} 
Deste deslocamento em direção ao mais originário resultará na promoção do futuro ao lugar até então ocupado pelo presente e uma reorientação completa das relações entre as três dimensões do tempo. 0 que exigirá o abandono mesmo dos termos 'futuro', 'passado' e 'presente' que Agostinho não acreditou dever pôr em questão por respeito à língua ordinária, a despeito de sua audácia em falar de presente do futuro, presente do passado e presente do presente.

(RICOEUR, 1985, p. 126)

Podendo-se afirmar também que:

É evidente que o tempo e as suas modulações tais como Aristóteles concebe, em termos do agora, número e movimento em um espaço geométrico não é idêntico à temporalidade "desespacializada" de suas ecstases, bem como a "instantaneidade" não é o agora, o "vir-a-ser" não é o "ainda-não-agora" e o "ter-sido" não é o "não-mais-agora".

(MARX, 1961, p. 110)

Além disso, não há lugar do tempo, pois o tempo não é espacializável. Não há presente que eternamente acontece, porque o tempo possui uma origem clara que não é a própria presença que se volta até si mesma; mas a natureza ekstática, para fora de si, o adiantar-se em relação ao futuro seria a origem-criativa do tempo que torna-se presente somente porque instantaneamente o passado se atualiza pela força catalizante do futuro.

Heidegger, dessa maneira, revoluciona o conceito de presente próprio à tradição ontológica da ideia de tempo, tornando-o resultado inacabado do tempo, não mais a sua origem imutável eterna ou conceitual. A partir de Martin Heidegger e sua pequena “revolução copernicana" sobre a ideia de tempo, justificada teoricamente e explicada como tal, então, pode-se dizer que o modus temporal presente é de fato inacabado por meio da relação necessária com sua origem: a força existencial que se produz no intercurso da unidade futuro-passado. 


\section{A epistemologia e seu pressuposto ontológico}

Toda proposição epistemológica, naturalmente, pressupõe uma estrutura ontológica.

O presente pela proposta de Agostinho é eterno, ele não é inacabado, transitório, conforme poderíamos, hoje, interpretar, conforme sua origem teológica anuncia. Tal visada sobre o texto agostiniano só é possível a partir ou através de uma série de modificações conceituais, tal como propõe Martin Heidegger. O presente é, como eternidade, uma unidade completa, acabada e que se mostra assim, mesmo que de modo provisório, pois ele, na verdade, é unicamente estático; configura-se de modo harmônico como a origem do tempo que nunca excede os seus próprios limites, quer dizer, não se transforma, impossibilitando, teoricamente, uma relação não mediada por si mesmo com o passado ou o futuro, tornando a possibilidade ou mesmo a existência do que se chama passado e futuro conceitualmente comprometida. O presente seria a estabilidade do tempo, pois o presente nunca se torna passado, nem nunca se torna futuro, ele é a expressão clara do ser e de acordo com sua natureza imutável da ontologia tradicional.

Se há, então, uma motivação para o aparecimento da História do Tempo Presente que vai além da transformação do papel social do historiador no século XX - que impõe a tarefa de interpretar os fatos políticos atuais e se envolver eticamente com os eventos perscrutados (Cf. RANGEL, ARAUJO, 2015) -, esta motivação é ontológica, através da pequena reviravolta sobre a ideia de tempo inaugurada por Heidegger ao transformar o presente em modalidade de tempo dinâmica em relação indissociável com o futuro e o passado, sendo a determinação existencial da relação futuro-passado a origem da presença e existência do tempo, como resultado transitório de fato das relações entre todas as modulações temporais existentes como unidade instantânea. Tal operação ontológica produz o efeito epistemológico imediato averiguado na obra de Reinhart Koselleck, que, por sua vez, lega à Teoria da História os conceitos meta-históricos espaçode-experiência e horizonte-de-expectativa, declaradamente heideggerianos e gadamerianos (Cf. 2000, p. 355). Isto é, a revolução ontológica heideggeriana sobre a ideia de tempo conhece uma elaboração apropriada para o conhecimento histórico em Wahrheit und Methode (1960), de Hans-Georg Gadamer, sendo reelaborada para a Teoria 
uma fusão de horizontes de futuro e passado, em constante mudança (Cf. GADAMER, 1993, p. 417), atuantes enquanto forças existenciais segundo a unidade futuro-passado proposta por Heidegger.

A noção de presente, anunciada por François Dosse, como o conceito operado epistemologicamente pela historiografia do Tempo Presente deve a Koselleck, mais do que a qualquer outro, conforme o próprio argumento de Dosse e sua interpretação ricoeuriana, a capilaridade no ambiente francês, bem como a estruturação epistemológica de sua tarefa (Cf. DOSSE, 2012, p. 20). Todavia, o "Tempo Presente" ao qual esta historiografia se refere não se trata de uma "lacuna" a ser preenchida, conforme propõe Dosse, mas de certa condição da existência a ser analisada, a condição da presença do futuro-passado, o problema fundamental que se coloca como pressuposto desta maneira de se pensar a História.

\section{Referências}

AGOSTINHO. Confissões XI. In: REY PUENTE, Fernando; BARACAT JÚNIOR, José. Tratados sobre o tempo: Aristóteles, Plotino e Agostinho. Belo Horizonte: Editora UFMG, 2014.

AUGUSTIN. Confessions. Tome II : Livre IX-XIII (Texte établi et traduit par : Pierre De LABRIOLLE). Paris: Les Belles Lettres, 1926.

AUGUSTINE. Confessions - Volume II - Books 9-13 (Edited and translated by Carolyn J.-B. Hammond). Cambridge: Harvard University Press, 2016.

AQUINO. Suma teológica. São Paulo: Edições Loyola, 2006.

ARISTÓTELES. Tratado do Tempo, Física IV 10-14. In: REY PUENTE, Fernando; BARACAT JÚNIOR, José (Orgs.). Tratados sobre o tempo: Aristóteles, Plotino e Agostinho. Editora UFMG: Belo Horizonte, 2014. 
ARISTOTLE. Physics. Cambridge: Harvard University Press, 1957.

ARISTOTE. Physique. Tome I: Livres I-IV (Texte établi et traduit par : Henri CARTERON). Paris : Les Belles Lettres, 1926.

ARISTOTE. Catégories (Texte établi et traduit par : Richard BODÉÜS). Paris : Les Belles Lettres, 2002

ASSMANN, J. et al. "Zeit”. In: RITTER, Joachim ; GRÜNDER, Karlfried ; GABRIEL, Gottfried (Hgg.): Historisches Wörterbuch der Philosophie - Bd. 12. Basel: Schwabe \& Co., 2004.

CALLAHAN, John. Four views of time in ancient philosophy. Cambridge: Harvard University Press, 1948.

CONEN, Paul. Die Zeittheorie des Aristoteles. München: C. H. Beck'sche Verlagsbuchhandlung, 1964.

CROCE, Benedetto. La storia como pensiero e come azione.Laterza: Bari, 1943.

DE CARVALHO, Augusto. História do passado: da conceitualização tradicional à reconfiguração em Walter Benjamin, Martin Heidegger e Sigmund Freud. Orientadora: Heloísa Maria Murgel Starling. 2017. 392f. Tese (Doutorado em História) - Faculdade de Filosofia e Ciências Humanas, Universidade Federal de Minas Gerais, Belo Horizonte, 2017.

DERRIDA, Jaques. Marges de la Philosophie. Paris : Les Éditions de Minuit, 1972.

DOSSE, François. História do Tempo Presente e Historiografia. Tempo \& Argumento, Florianópolis, v. 4, v. 1, jan./jun., 2012.

DROYSEN, Johann Gustav. Historik: Rekonstruktion der ersten vollständigen Fassung der Vorlesungen (1857) Grundriß der Historik in der ersten handschriftlichen (1857/1858) und in der letzten gedruckten Fassung (1882). Textausgabe von Peter Leyh. Stuttgart: Fromann-Holzboog, 1977.

EINSTEIN, Albert. Bemerkungen zu den in diesem Bande vereinigten Arbeiten. In: SCHILPP, P. A. Albert Einstein als philosoph und naturforscher. Braunschweig: Vieweg, 1979.

FICO, Carlos. História que temos vivido. In: História \& Narrativa: A ciência e a arte da escrita histórica. Petrópolis - RJ: Editora Vozes, 2016. 
GADAMER, Hans-Georg. L'expérience intérieure du temps et l'échec de la réflexion dans la pensée occidental. In: Le temps et les philosophes. Payot/Unesco: Paris, 1978.

GADAMER, Hans-Georg. Wahrheit und Methode. Hermeneutik II . In: Gesammelte Werke (Band 2). Tübingen: J. C. B Mohr (Paul Siebeck), 1993.

HEGEL, Georg Wilhelm Friedrich. Werke in 20 Bänden mit Registerband. Frankfut am Main: Suhrkamp, 1986.

HEIDEGGER, Martin. Gesamtausgabe (102 Bänden). Frankfurt am main: Vittorio Klostermann, (1977-). (GA)

HEIDEGGER, Martin. Ser e tempo [Sein und Zeit] (edição bilíngue).Trad. de Fausto Castilho. São Paulo: Editora da Unicamp; Vozes, 2012.

HEIDEGGER, Martin. Os problemas fundamentais da fenomenologia. Trad. Marco Casanova. Petrópolis: Editora Vozes, 2005.

HUME, David. A Treatise of human nature. Oxford: Clarendon Press, 1739.

HUSSERL, Edmund. Vorlesungen zur Phänomenologie des inneren Zeitbewußtseins. Freiburg: Max Niemeyer Verlag, 1928.

JAMES, William. The principles of psychology. New York: Henry Holt and Co., 1890.

KOCKELMANS, Joseph. Heidegger on time and being. In: MACANN, Christopher (Ed.). Martin Heidegger: critical assessements (vol 1).New York, London: Routledge, 1992.

KOSELLECK, Reinhart. Vergangene: Zukunft. Zur Semantik geschichtlicher Zeiten. Frankfurt am Main: Suhrkamp, 2000.

LEVINAS, Emmanuel.Dieu, la mort et le temps. Paris : Grasset \& Fasquelle, 1993.

LLOYD, G. E. R. Le temps das la pensée grecque. In: RICOEUR, Paul. Les Cultures et le Temps. Paris : Payot; Unesco, 1975.

MARX, Werner. Heidegger und die Tradition. Eine problemgeschichtliche. Einführung in die Grund bestimmungen des Seins. Stuttgart: Kohlhammer Verlag, 1961.

MCTAGGART, John Ellis. The Unreality of time. Mind, n. 17, 1908. 
MEIJERING, E. Augustin über Schöpfung, Ewigkeit und Zeit. Das elfte Buch der Bekenntnisse. Leiden, 1979.

O’DONNELL, James. Augustine Confessions (III - Commentary on Books 8-13). Oxford: Claredon Press, 1992.

PLATÃO. Timeu. In: PLATÃO. Diálogos V. Trad. Edson Bini. São Paulo: Edipro, 2010.

RANGEL, M. de M.; ARAUJO, V. L. de. Apresentação - teoria e história da historiografia: do giro linguístico ao giro ético-político. História da historiografia, Ouro Preto, n. 17, p. 318332, abr. 2015.

TESKE, Roland. Paradoxes of time in Saint Augustine (the aquinas lecture). Milwaukee: Marquette University Press, 1996.

RICOEUR, Paul. Temps e Récit III. Le temps raconté. Paris: Éditions du Seuil, 1985.

WEIGELT, Charlotta. Aristotle's Logical Analysis of Motion in Physics I. In: SCHUBACK, Márcia sá Cavalcante; PEREIRA, Luiz Carlos. Time and Form: Essays on Philosophy, Logic, Art, and Politics. Stokholm: Axl Books, 2014.

WEIS, Josef. Die Zeitontologie des Kirchenlehrers Augustinus nach seinen

Bekenntnissen (Europäische Hochschulschriften - Reihe XX : Band 135). Frankfurt am Main; Bern; New York: Peter Lang, 1984.

ZWART. P. J. The flow of time. Synthese, $n^{\circ} 24,1972$.

Recebido em 26/02/2018 Aprovado em 19/06/2018

Universidade do Estado de Santa Catarina - UDESC

Programa de Pós-Graduação em História - PPGH

Revista Tempo e Argumento Volume 10 - Número 24 - Ano 2018 tempoeargumento@gmail.com 